\title{
Stability of Calcium Ion Battery Electrolytes: Predictions from Ab Initio Molecular Dynamics Simulations
}

Sharma S. R. K. C. Yamijala, ${ }^{1,2,3}$ Hyuna Kwon, ${ }^{1}$ Juchen Guo, ${ }^{1,}$ 2, 3,* Bryan M. Wong ${ }^{1,2,3, *}$

${ }^{1}$ Department of Chemical \& Environmental Engineering, ${ }^{2}$ Materials Science \& Engineering Program, and ${ }^{3}$ Department of Chemistry, University of California-Riverside, Riverside, CA, USA.

* Corresponding authors

E-mails: iguo@engr.ucr.edu, bryan.wong@ucr.edu

\begin{abstract}
Multivalent batteries, such as magnesium-ion, calcium-ion, and zinc-ion batteries, have attracted significant attention as next-generation electrochemical energy storage devices to complement conventional lithium-ion batteries (LIBs). Among them, calcium-ion batteries (CIBs) are the least explored due to the difficult reversible Ca deposition-dissolution. In this work, we examined the stability of four different $\mathrm{Ca}$ salts with weakly coordinating anions and three different solvents commonly employed in existing battery technologies to identify suitable candidates for CIBs. By employing Born-Oppenheimer molecular dynamics (BOMD) simulations on salt-Ca and solvent$\mathrm{Ca}$ interfaces, we find that the tetraglyme solvent and carborane salt are promising candidates for CIBs. Due to the strong reducing nature of the calcium surface, the other salts and solvents readily decompose. We explain the microscopic mechanisms of salt/solvent decomposition on the Ca surface using time-dependent projected density of states, time-dependent charge-transfer plots, and climbing-image nudged elastic band calculations. Collectively, this work presents the first mechanistic assessment of the dynamical stability of candidate salts and solvents on a $\mathrm{Ca}$ surface using BOMD simulations, and provides a predictive path toward designing stable electrolytes for CIBs.
\end{abstract}

Keywords: Ab initio molecular dynamics, Multivalent metal-ion batteries, Calcium ion batteries, Born-Oppenheimer molecular dynamics, Salt stability, Electrolyte stability, Time-dependent PDOS. 


\section{Introduction}

Modern technological advancements, including mobile phones, laptops, and electric automobiles, critically depend on efficient, rechargeable energy storage devices (batteries). Among the various candidate battery technologies, lithium-ion batteries (LIBs) are at the forefront of research and consumer use; ${ }^{1-4}$ however, the raw materials used to construct LIBs (namely, lithium and cobalt) are neither earth-abundant nor are they evenly distributed globally (creating geopolitical tensions, particularly in the case of Co).$^{5-8}$ The anticipated depletion in raw materials, along with rising demand for energy storage devices (due to the rapid adoption of electric vehicles), has prompted significant interest in beyond-lithium ion batteries. ${ }^{9}$ Among the viable alternatives to LIBs, calcium ion batteries (CIBs) - a subset of multivalent cation (such as magnesium, zinc, aluminum, etc.) batteries, have garnered significant attention due to their high gravimetric and volumetric energy densities, non-toxicity, and earth abundance. , $^{2,3,6,10-14}$

Calcium is the fifth most abundant element in the earth's crust with a standard reduction potential of just $0.17 \mathrm{~V}$ above lithium. Accordingly, it can generate a large cell potential compared to other multivalent cation elements such as $\mathrm{Mg}$ or Al. Similarly, due to its lower charge polarization character, a $\mathrm{Ca}^{2+}$ ion should be more mobile in cathode materials compared to $\mathrm{Mg}^{2+}$ and $\mathrm{Al}^{3+}$ ions. ${ }^{2,3,10-14}$ Despite these advantages, most research on multivalent cation batteries has focused on magnesium. This shift in interest towards magnesium ion batteries (MIBs) is primarily due to the lack of stable and efficient electrolytes for CIBs that can show reversible plating and stripping of calcium. ${ }^{12,13}$ It is also important to note that while the decomposition of the electrolytes at the anode (which leads to the formation of the so-called solid-electrolyte interphase (SEI)) is an advantage for LIB technology, it is detrimental for CIBs. ${ }^{2,10,11,15}$ This difference occurs because Li-ions can readily migrate through the SEI, whereas $\mathrm{Ca}$ ions cannot. ${ }^{15}$ As such, identifying appropriate electrolytes that can either form a Ca-ion-permeable SEI or does not form an SEI altogether, is one of the key thrusts in developing promising CIBs. ${ }^{16}$

Early studies, such as the seminal work by Aurbach et al., ${ }^{15}$ concluded that it is impossible to deposit calcium on either noble-metal or calcium-metal electrodes with typical battery electrolytes. However, studies in the past five years have shown significant progress in reversible plating and stripping of calcium using a few salt and solvent systems. ${ }^{10-13}$ For example, in their pioneering work in 2016, Ponrouch et al. used calcium tetrafluoroborate $\left(\mathrm{Ca}\left(\mathrm{BF}_{4}\right)_{2}\right)$ salt in a mixture of ethylene carbonate (EC) and propylene carbonate (PC) solvents to reversibly deposit $\mathrm{Ca}$ at moderate temperatures $\left(75-100{ }^{\circ} \mathrm{C}\right) .{ }^{11}$ It is important to note that the authors could not deposit $\mathrm{Ca}$ from calcium bis(trifluoromethanesulfonyl)imide ( $\mathrm{Ca}[\mathrm{TFSI}]_{2}$ ) salt using the same solvent mixture and elevated temperatures. Later, Wang et al. demonstrated the reversible plating and stripping of calcium at room temperature using $\mathrm{Ca}\left(\mathrm{BH}_{4}\right)_{2}$ in tetrahydrofuran (THF). ${ }^{10}$ While these works successfully established the feasibility of reversible Ca deposition, the $\mathrm{BH}_{4}{ }^{-}$and $\mathrm{BF}_{4}{ }^{-}$ anion used in these works is known to suffer from intrinsic instability towards oxidation. ${ }^{12,13}$

Earlier work on MIBs showed that bulkier anions, such as closo-carboranes (for example, $\left.\left[\mathrm{CB}_{11} \mathrm{H}_{12}\right]^{-}\right)^{17}$ and alkoxyborates ([B(hfip) $\left.\left.]_{4}\right]^{-}\right),{ }^{18}$ possess superior oxidative stability. The bulkiness of these anions also enables charge delocalization over a large spatial extent, further enhancing 
the cation mobility due to decreased anion-cation interactions. Inspired by these previous findings on MIBs, both $\mathrm{Li}$ et al. $^{12}$ and Shyamsunder et al. ${ }^{13}$ considered the calcium tetrakis(hexafluoroisopropoxy)borate salt, $\mathrm{Ca}\left[\mathrm{B}(\mathrm{hfip})_{4}\right]_{2}$, in dimethoxyethane solvent (commonly known as monoglyme) and showed facile calcium deposition with high ionic conductivities (> 8 $\mathrm{ms} \mathrm{cm}^{-1}$ ) and high anionic oxidation stability (up to $4.5 \mathrm{~V}$ versus $\mathrm{Ca}$ ). However, even with these bulky anions, side products such as $\mathrm{CaF}_{2}$ were observed during reduction. ${ }^{13}$ While earlier work on magnesium carborane salts did not show any side products, ${ }^{17}$ to the best of our knowledge, the successful synthesis of calcium carborane salts has not yet been reported. As such, despite considerable breakthroughs in the development of CIBs, there is significant room to improve the stability of electrolytes. Moreover, the decomposition mechanisms of the salt/solvent at the calcium anode are still not fully understood, and a deep understanding of this effect is essential for probing the composition of the SEl, which further affects the plating/stripping of Ca. Furthermore, the decomposed products would provide fundamental insight into the physical and chemical properties of the electrolytes to further enhance their efficiency.

To bridge this knowledge gap, we have carried out density functional theory (DFT) and ab initio molecular dynamics (AIMD) calculations to understand the reductive stability of four salts: (1) calcium hexafluorophosphate $\left(\mathrm{Ca}\left[\mathrm{PF}_{6}\right]_{2}\right)$, (2) calcium closo-monocarborane $\left(\mathrm{Ca}\left[\mathrm{CB}_{11} \mathrm{H}_{12}\right]_{2}\right)$, (3)
calcium
bis(trifluoromethanesulfonyl)imide
$\left(\mathrm{Ca}[\mathrm{TFSI}]_{2}\right), \quad$ and
(4) calcium tetrakis(hexafluoroisopropoxy)borate $\left(\mathrm{Ca}\left[\mathrm{B}(\mathrm{hfip})_{4}\right]_{2}\right)$, at both 300 and $500 \mathrm{~K}$. Although the $\mathrm{Ca}\left[\mathrm{CB}_{11} \mathrm{H}_{12}\right]_{2}$ salt has not been synthesized, we provide predictions of its stability as a promising candidate salt, based on the success of its magnesium analogue. Apart from these salts, we also investigated the three most commonly used organic solvents in battery systems, including EC, PC, and tetraethylene glycol dimethyl ether (G4). Together, these ab initio calculations provide a comprehensive understanding of the various decomposition pathways of electrolytes on the calcium surface. Most importantly, our calculations provide essential design principles to enable a rational path towards rechargeable $\mathrm{Ca}$-ion batteries.

\section{Computational Details}

Our electronic structure and Born-Oppenheimer molecular dynamics (BOMD) simulations were performed with Kohn-Sham density functional theory using the Perdew-Burke-Ernzerhof exchange-correlation functional ${ }^{19}$ and molecularly optimized double-zeta quality (DZVP) basissets ${ }^{20}$ as implemented in the CP2K software package. ${ }^{21}$ For the auxiliary plane-wave (PW) basis, we used 300 Ry for the PW energy cutoff and 60 Ry for the reference grid cutoff. GoedeckerTeter-Hutter pseudopotentials, ${ }^{22,23}$ which are compatible with the employed basis-sets, were used for all the elements. Dispersion interactions were included using Grimme's D3-dispersion correction. ${ }^{24}$ Due to the large supercell sizes considered in our simulations (see the Supporting Information), the Brillouin zone integration was performed only at the $\Gamma$-point. All optimization calculations were converged until the forces on all atoms were less than $0.02 \mathrm{eV} / \AA$. Optimized geometries of the salt-surface/solvent-surface interfaces were subsequently used as the initial configurations for the NVT simulations. For predicting reaction barriers, we carried out climbing 
image nudged elastic band ( $\mathrm{Cl}-\mathrm{NEB})$ calculations with a minimum of four images between the reactants and products.

BOMD simulations were performed in a canonical ensemble (NVT) at both 300 and 500 $\mathrm{K}$, and these temperatures were maintained using the Nosé-Hoover thermostat of chain length three. The equations of motion were integrated with a 1-fs time step (by using a tritium mass for the hydrogen atoms). Time-dependent charge-transfer analyses were conducted using Mulliken charges, which were printed at each time-step. Similarly, time-dependent projected density of states (TD-PDOS) analyses were conducted at specific time-steps. Geometries at these timesteps were read from the trajectory files, and wavefunction (SCF) optimization was performed. Additional computational setup parameters and details are given in the Supporting Information.

\section{Results and Discussion}

(a)

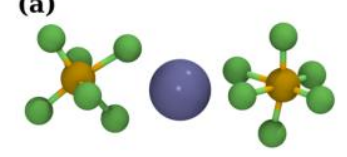

(c)

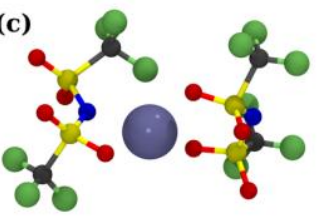

(b)

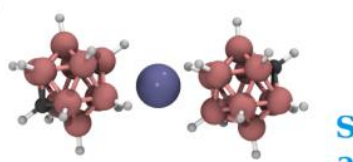

(d)

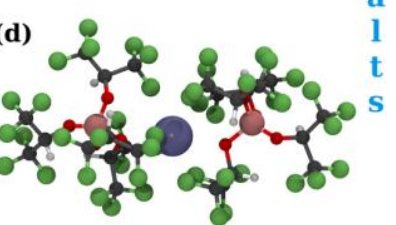

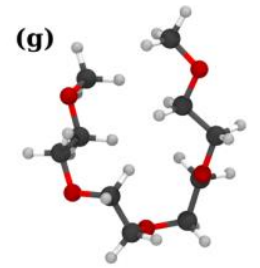

(f)

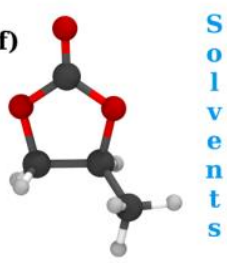

H B C O N F P C C

Figure 1: Various salts and solvents examined in this work. Salts: (a) calcium hexafluorophosphate $\left(\mathrm{Ca}\left[\mathrm{PF}_{6}\right]_{2}\right)$, (b) calcium closo-monocarborane $\left(\mathrm{Ca}\left[\mathrm{CB}_{11} \mathrm{H}_{12}\right]_{2}\right)$, (c) calcium bis(trifluoromethanesulfonyl)imide $\left(\mathrm{Ca}[\mathrm{TFSI}]_{2}\right)$, and (d) calcium tetrakis(hexafluoroisopropoxy)borate $\left(\mathrm{Ca}\left[\mathrm{B}(\mathrm{hfip})_{4}\right]_{2}\right)$. Solvents: $(\mathrm{e})$ ethylene carbonate $(\mathrm{EC})(\mathrm{f})$ tetraethylene glycol dimethyl ether (G4) (g) propylene carbonate (PC).

Figure 1 depicts all the salts and solvents studied in this work. In addition to traditional anions such as $\mathrm{PF}_{6}$ and TFSI, we also inspected bulkier anions with higher redox stabilities, namely, alkoxy borates and carboranes. Similarly, for solvents, we considered both carbonates as well as ethers. Most of these solvent and salt-anion combinations continue to be used in existing battery technologies. ${ }^{25-31}$ For example, EC, PC, and glyme solvents, along with $\mathrm{PF}_{6}$ and 
TFSI anions, have previously been used in both LIB and MIB technologies. ${ }^{25-31}$ Similarly, recent studies showed that both $\mathrm{Mg}\left[\mathrm{B}(\mathrm{hfip})_{4}\right]_{2}$ and $\mathrm{Mg}\left[\mathrm{CB}_{11} \mathrm{H}_{12}\right]_{2}$ are more suitable than $\mathrm{Mg}[\mathrm{TFSI}]_{2}$ for reversible plating and stripping of $\mathrm{Mg}$ in MIBs. ${ }^{17,18}$ However, except for a few experiments, ${ }^{11-13}$ most of these electrolytes have not been entirely explored in the context of ClBs. As such, considering their importance in battery technologies, we examined their reductive stability on the Ca surface. We first present our results on salt-Ca interfaces and then proceed to a discussion of our solvent-Ca interface calculations.

\section{Stability of Salts on the Calcium Electrode Surface}

To investigate the stability and reactivity of electrolytes on $\mathrm{Ca}$ electrode surfaces, we carried out AIMD simulations on the optimized electrode surface-electrolyte models. Figure 2 depicts the geometries of each salt at the initial and final steps of an NVT simulation, conducted at $300 \mathrm{~K}$, on a Ca surface. As shown in Figs. $2 \mathrm{~b}$ and $2 \mathrm{~d}$, both $\mathrm{Ca}[\mathrm{TFSI}]_{2}$ and $\mathrm{Ca}\left[\mathrm{PF}_{6}\right]_{2}$ completely decomposed, suggesting their instability on a $\mathrm{Ca}$ surface even at room temperature. The decomposed salt species penetrated the second layer of the Ca surface and formed various products such as $\mathrm{CaF}_{2}, \mathrm{CaO}$, CaS, etc. Our results are in well-agreement with several earlier experiments, which showed the formation of $\mathrm{CaF}_{2}$ with fluorine-containing salts. ${ }^{2,11,13,32}$ Moreover, the complete decomposition of TFSI anions in our simulations explains earlier experimental results ${ }^{2,11}$ showing that reversible plating and stripping of $\mathrm{Ca}$ was impossible with the $\mathrm{Ca}[\mathrm{TFSI}]_{2}$ salt. Interestingly, we find that the initial stages of the decomposition mechanism of TFSI anions on the Ca surface are similar to those observed on the Li surface. ${ }^{33,34}$ Specifically, on both surfaces, the $\mathrm{S}_{-} \mathrm{CF}_{3}$ bond dissociated first, followed by the dissociation of the C-F bonds in the detached $\mathrm{CF}_{3}$ group. As such, our results indicate that the $\mathrm{S}-\mathrm{C}$ bond is prone to reductive fragmentation, which further initiates the complete decomposition of the TFSI anion on a $\mathrm{Ca}$ surface.

Although there have been experimental studies on the synthesis of $\mathrm{Ca}\left[\mathrm{PF}_{6}\right]_{2},{ }^{35,36}$ to the best of our knowledge, there has been no successful demonstration of reversible $\mathrm{Ca}$ deposition using $\mathrm{Ca}_{[}\left[\mathrm{PF}_{6}\right]_{2}$ on a calcium electrode. Based on our BOMD simulations, we also predicted that $\mathrm{Ca}\left[\mathrm{PF}_{6}\right]_{2}$ is ill-suited for rechargeable ClBs since it completely decomposes on a Ca surface. $\mathrm{A}$ few studies showing reversible $\mathrm{Ca}$ deposition using $\mathrm{Ca}_{[}\left[\mathrm{PF}_{6}\right]_{2}$ on non-calcium electrodes also observed the formation of $\mathrm{CaF}_{2}$, confirming its poor stability. ${ }^{14,32}$ 
(a)

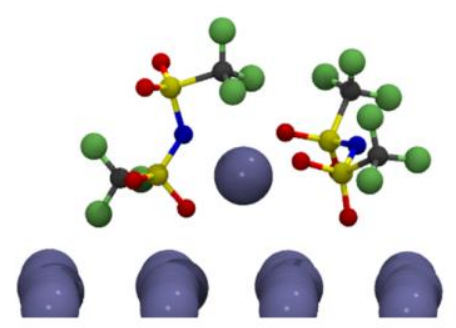

(c)

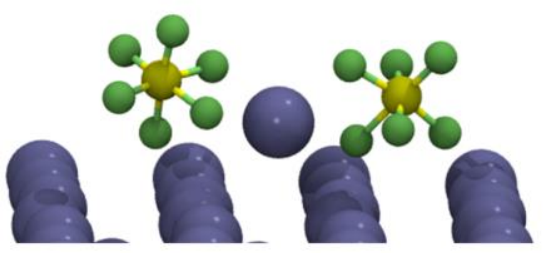

(e)

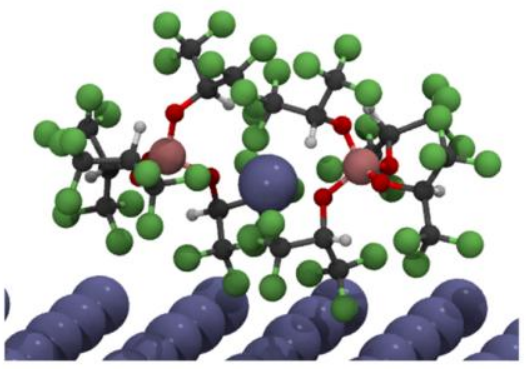

(g)

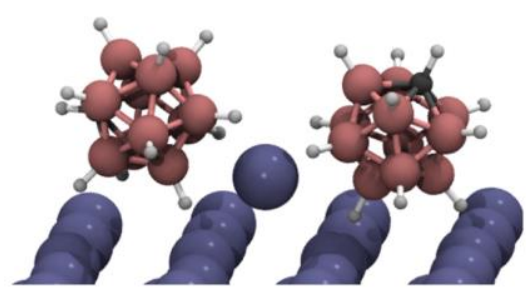

(b)

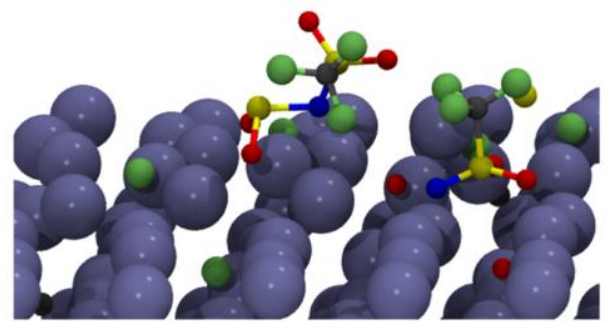

(d)

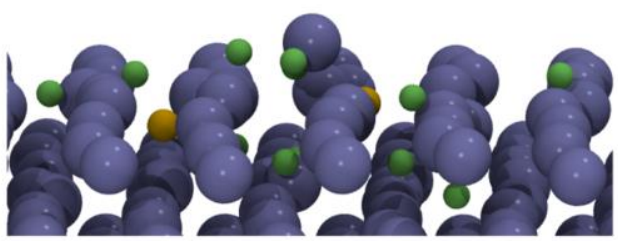

(f)

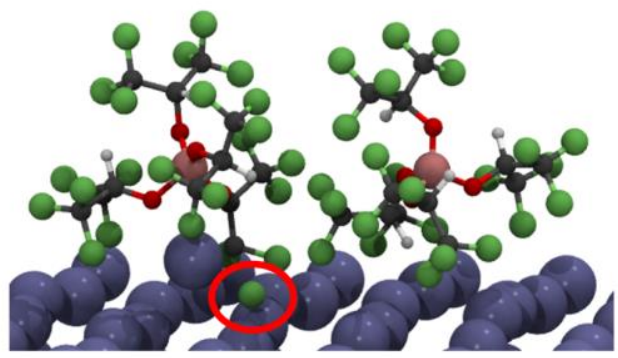

(h)

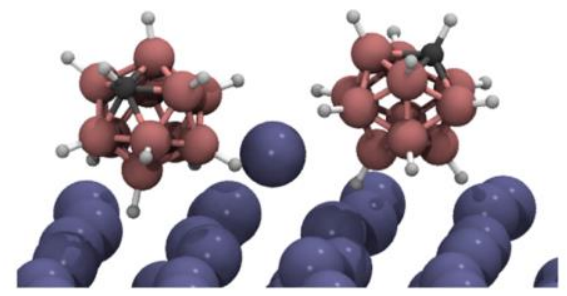

Figure 2: Geometries of different salt molecules on a Ca surface at the beginning (a, c, e, and $\mathrm{g}$ ) and end (b, d, f, and h) of an NVT simulation performed at $300 \mathrm{~K}$. Simulation snapshots with $\mathrm{Ca}\left[\mathrm{TFSI}_{2}, \mathrm{Ca}\left[\mathrm{PF}_{6}\right]_{2}, \mathrm{Ca}[\mathrm{B} \text { (hfip) }]_{2}\right.$, and $\mathrm{Ca}\left[\mathrm{CB}_{11} \mathrm{H}_{12}\right]_{2}$ salts were taken at (b) 5 , (d) 5 , (f) 10 , and (h) 15 picoseconds, respectively. While $\mathrm{Ca}[\mathrm{TFSI}]_{2}$ and $\mathrm{Ca}\left[\mathrm{PF}_{6}\right]_{2}$ completely decomposed at 300 $\mathrm{K}$ (panels $\mathrm{b}$ and $\mathrm{d}$ ), $\mathrm{Ca}\left[\mathrm{B}(\mathrm{hfip})_{4}\right]_{2}$ and $\mathrm{Ca}\left[\mathrm{CB}_{11} \mathrm{H}_{12}\right]_{2}$ remained mostly intact (panels $\mathrm{f}$ and $\mathrm{h}$ ) throughout the simulation. In panel $f$, the red circle shows the fragmentation of one of the carbon-fluorine bonds in the $\mathrm{Ca}\left[\mathrm{B} \text { (hfip) }{ }_{4}\right]_{2}$ salt, which occurred at $\sim 2$ ps (see Figure 3 and the main text for details). After that fragmentation event, the structure remained intact for more than 8 ps.

Unlike $\mathrm{Ca}[\mathrm{TFSI}]_{2}$ and $\mathrm{Ca}\left[\mathrm{PF}_{6}\right]_{2}$, both $\mathrm{Ca}\left[\mathrm{B}(\mathrm{hfip})_{4}\right]_{2}$ and $\mathrm{Ca}\left[\mathrm{CB}_{11} \mathrm{H}_{12}\right]_{2}$ remained mostly intact throughout the simulation (see Figs. $2 f$ and $2 h$ ). With $\mathrm{Ca}\left[\mathrm{B}(\mathrm{hfip})_{4}\right]_{2}$, we observed the fragmentation of a C-F bond during the first 2 ps of the simulation, with no further bond cleavage until the end of the simulation (10 ps). This observation supports recent experiments in two aspects: ${ }^{12,13}$ (1) our simulations validate that $\left.\mathrm{Ca}[\mathrm{B} \text { (hfip) }]_{2}\right]_{2}$ is not entirely stable on a Ca surface; in other words, a 
few of the $\mathrm{C}-\mathrm{F}$ bonds are cleaved to form $\mathrm{CaF}_{2},{ }^{13}$ and (2) our predictions confirm that only minor quantities of $\mathrm{CaF}_{2}$ will be formed when $\mathrm{Ca}\left[\mathrm{B}(\mathrm{hfip})_{4}\right]_{2}$ is used, unlike other fluorine-containing salts. ${ }^{12}$ Specifically, earlier experiments showed that only a $7 \%$ molar ratio of $\mathrm{CaF}_{2}$ was formed with $\mathrm{Ca}\left[\mathrm{B} \text { (hfip) }{ }_{4}\right]_{2},{ }^{12}$ but more than $30 \%$ was observed with $\mathrm{Ca}\left(\mathrm{BF}_{4}\right)_{2} .{ }^{11}$ Although an exact percentage was not reported for $\mathrm{Ca}[\mathrm{TFSI}]_{2}$ and $\mathrm{Ca}\left[\mathrm{PF}_{6}\right]_{2}$, we can accurately project that much higher portions (>50\%) of $\mathrm{CaF}_{2}$ would be formed (since these salts do not exhibit a reversible $\mathrm{Ca}$ deposition). Our simulations also predict a lower decomposition rate for $\mathrm{Ca}[\mathrm{B} \text { (hfip) }]_{2}$ than other fluorine-containing salts in our study; i.e., we observed a complete decomposition of $\mathrm{Ca}[\mathrm{TFSI}]_{2}$ and $\mathrm{Ca}\left[\mathrm{PF}_{6}\right]_{2}$ in $5 \mathrm{ps}$, but $\mathrm{Ca}\left[\mathrm{B}(\text { hfip) })_{4}\right]_{2}$ remained almost intact until 10 ps (except for a single C-F bond dissociation, which occurred at around $2 \mathrm{ps}$ ).

Contrary to the fluorine-containing salts, we did not observe any bond cleavage in $\mathrm{Ca}\left[\mathrm{CB}_{11} \mathrm{H}_{12}\right]_{2}$ even up to $15 \mathrm{ps}$. As such, $\mathrm{Ca}\left[\mathrm{CB}_{11} \mathrm{H}_{12}\right]_{2}$ has superior stability among all the salts studied in this work. The exceptional stability of $\mathrm{CB}_{11} \mathrm{H}_{12}$ anion on a $\mathrm{Ca}$ surface is identical to earlier experiments with this anion on an Mg surface, where no side products were observed. ${ }^{17}$ The stability of $\mathrm{Ca}\left[\mathrm{B}(\text { hfip) })_{4}\right]_{2}$ and $\mathrm{Ca}\left[\mathrm{CB}_{11} \mathrm{H}_{12}\right]_{2}$ (compared to $\mathrm{Ca}[\mathrm{TFSI}]_{2}$ and $\mathrm{Ca}[\mathrm{PF} 6]_{2}$ ) was confirmed by carrying out 5 ps of an NVT simulation; however, to further confirm the robustness of our results, we increased the simulation duration to 10 and $15 \mathrm{ps}$, respectively. We also carried out additional BOMD simulations at a higher temperature of $500 \mathrm{~K}$, which further confirmed that the $\mathrm{CB}_{11} \mathrm{H}_{12}$ anion has remarkable stability compared to the other anions (see Figure $\mathrm{S} 1$ ).

After confirming the stability of the $\mathrm{Ca}\left[\mathrm{B}(\mathrm{hfip})_{4}\right]_{2}$ and $\mathrm{Ca}\left[\mathrm{CB}_{11} \mathrm{H}_{12}\right]_{2}$ salts on a Ca surface at both 300 and $500 \mathrm{~K}$, we turned our attention to understanding the stability differences among the four salts. Earlier theoretical studies on the interfaces of various electrolytes with $\mathrm{Li}$ or $\mathrm{Mg}$ surfaces suggested that the instability of an electrolyte was often associated with a substantial charge transfer (CT) across the interface..$^{33,37-39}$ As such, we first analyzed the time-dependent charge transfer (TD-CT) trends between each salt and the Ca surface to understand their redox stability at $300 \mathrm{~K}$. Following the usual convention, an anion is said to be reduced (oxidized) when it accepts (donates) electrons from the Ca surface, and its reductive (oxidative) stability is considered to be lower when it decomposes by accepting (donating) electrons. An anion that neither accepts nor donates an electron will have superior redox stability.

Figure 3 depicts the charge donated/gained by a fragment (a surface or a salt or their components). Except for the $\mathrm{CB}_{11} \mathrm{H}_{12}$ anion, there is an apparent charge transfer from the $\mathrm{Ca}$ surface (red line) to the anions (orange and green lines). In other words, three out of the four salts were reduced by the Ca surface. Also, both $\mathrm{Ca}[\mathrm{TFSI}]_{2}$ and $\mathrm{Ca}\left[\mathrm{PF}_{6}\right]_{2}$ acquired more charge (eight electrons) from the $\mathrm{Ca}$ surface than $\mathrm{Ca}[\mathrm{B} \text { (hfip) }]_{2}$ (two electrons) or $\mathrm{Ca}\left[\mathrm{CB}_{11} \mathrm{H}_{12}\right]_{2}$ (zero electrons), suggesting the lower reductive stability of the former salts. As such, among the anions that we studied, $\mathrm{CB}_{11} \mathrm{H}_{12}$ showed exceptional reductive stability followed by $\mathrm{B}(\mathrm{hfip})_{4}$.

It is important to note that when an anion was reduced, the electrons were primarily transferred from the top layer of the Ca surface, which is in direct contact with the salt. Also, we did not observe a considerable change in CT beyond 3 ps for any of our simulations. Similar TD- 
CT results were obtained for all salts at $500 \mathrm{~K}$ (see Figure S2), which showed a quicker CT from the Ca surface to the salt compared to $300 \mathrm{~K}$.

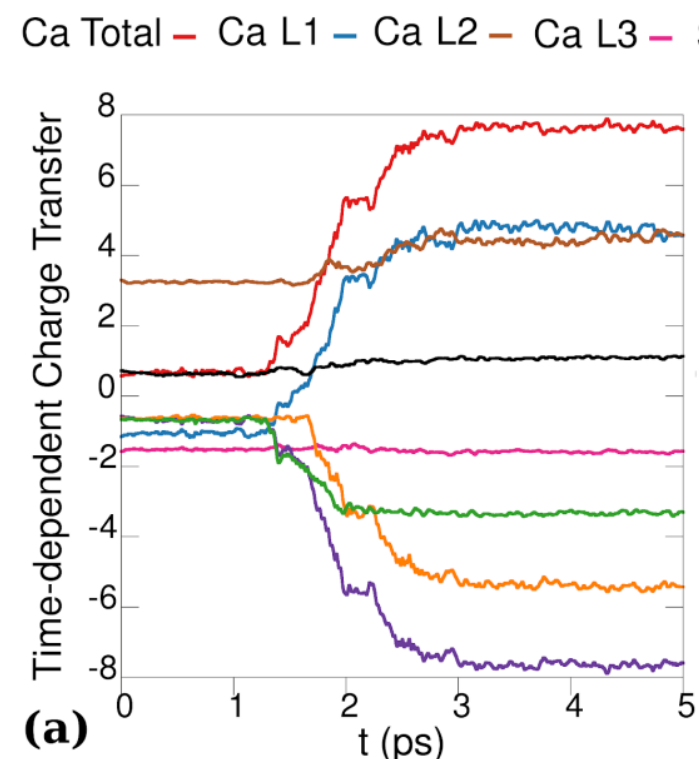

Ca[TFSI $]_{2}$

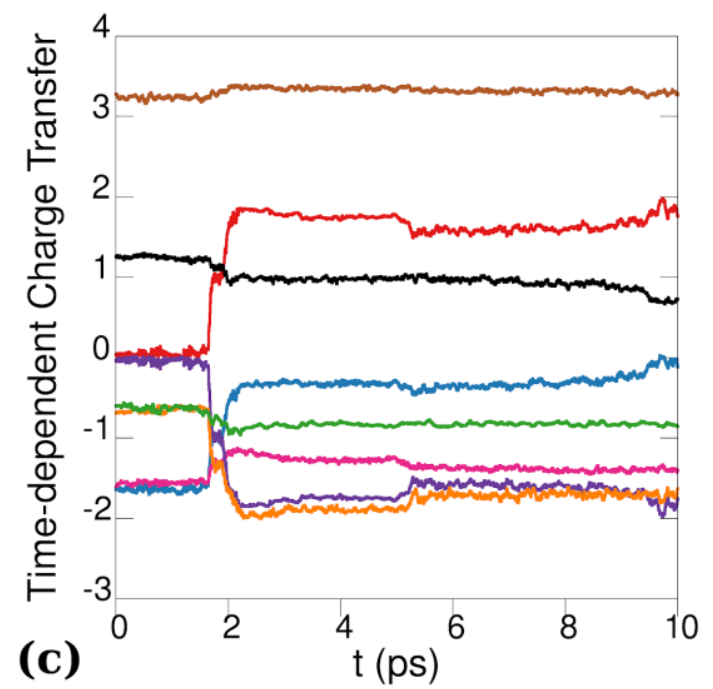

Ca[B(hfip) $\left.]_{4}\right]_{2}$

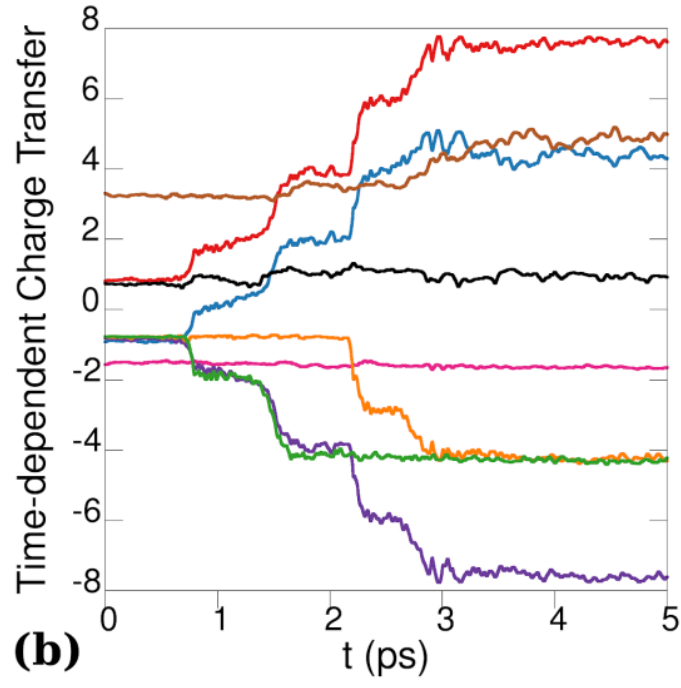

$\mathrm{Ca}\left[\mathrm{PF}_{6}\right]_{2}$

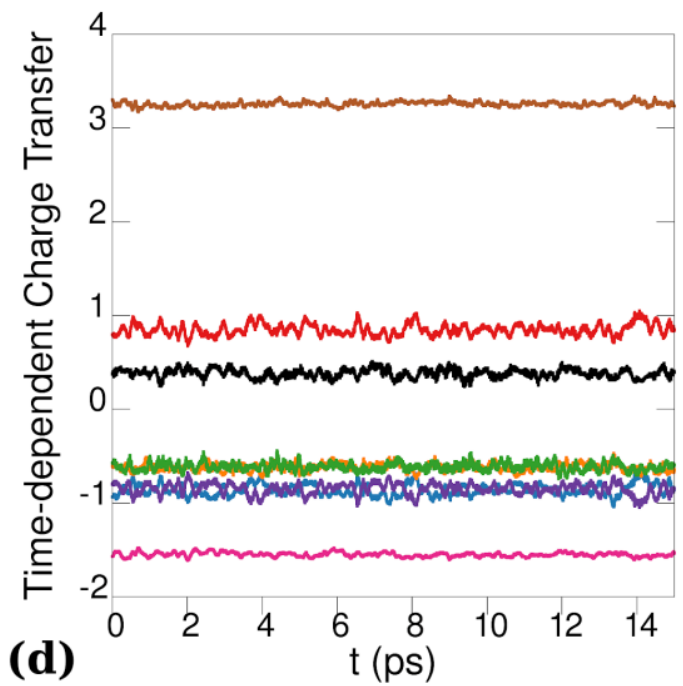

$\mathrm{Ca}\left[\mathrm{CB}_{11} \mathrm{H}_{12} \mathrm{l}_{2}\right.$

Figure 3: Time-dependent charge-transfer (TD-CT) from the calcium surface to (a) $\mathrm{Ca}[\mathrm{TFSI}]_{2}$, (b) $\mathrm{Ca}\left[\mathrm{PF} \mathrm{F}_{6}\right]_{2}$, (c) $\mathrm{Ca}\left[\mathrm{B}(\mathrm{hfip})_{4}\right]_{2}$, and (d) $\mathrm{Ca}\left[\mathrm{CB}_{11} \mathrm{H}_{12}\right]_{2}$ salts at $300 \mathrm{~K}$. In all panels, the amount of charge donated by a fragment is shown as a positive value, and the charge gained by a fragment is shown as a negative value on the vertical axis. In panels (a), (b), and (c), charge transfer from the surface to the salt is observed. Both the $\mathrm{Ca}[\mathrm{TFSI}]_{2}$ and $\mathrm{Ca}\left[\mathrm{PF}_{6}\right]_{2}$ salts gained $\sim 8$ electrons from the $\mathrm{Ca}$ surface in the first 3 ps of the simulation (panels $\mathrm{b}$ and d). Beyond 3 ps, only minor charge fluctuations are observed. Similarly, $\mathrm{Ca}\left[\mathrm{B}(\mathrm{hfip})_{4}\right]_{2}$ gained only two electrons (at around $2 \mathrm{ps}$ ), and $\mathrm{Ca}\left[\mathrm{CB}_{11} \mathrm{H}_{12}\right]_{2}$ did not accept any electrons (it has the highest 
reductive stability) from the Ca surface. In all cases, most of the electrons were transferred from the top layer ( $\mathrm{Ca} \mathrm{L1)}$ of the Ca surface to the salt.

While the TD-CT analysis confirms that $\mathrm{Ca}[\mathrm{TFSI}]_{2}$ and $\mathrm{Ca}\left[\mathrm{PF}_{6}\right]_{2}$ decompose via reduction, and $\mathrm{Ca}[\mathrm{B} \text { (hfip) }]_{2}$ and $\mathrm{Ca}\left[\mathrm{CB}_{11} \mathrm{H}_{12}\right]_{2}$ have superior reductive stability, it does not provide a microscopic rationale for the differences in stability among the salts. To obtain a more in-depth understanding, we studied the time-dependent projected density of states (TD-PDOS) of $\mathrm{Ca}(\mathrm{TFSI})_{2}$ and $\mathrm{Ca}\left[\mathrm{CB}_{11} \mathrm{H}_{12}\right]_{2}$ salts adsorbed onto the Ca-surface at $300 \mathrm{~K}$. Specifically, we examined changes in the lowest unoccupied molecular orbital (LUMO) of the salt as a function of time. When the Fermi level of the anode (i.e., the Ca surface) is above the LUMO of a salt, an electron can transfer from the Ca surface to the salt, resulting in the reduction of the salt. ${ }^{40}$ As such, a salt is stable towards anode reduction only when its LUMO is above the Fermi level of the anode. Figure 4 presents the TD-PDOS plots of $\mathrm{Ca}[\mathrm{TFSI}]_{2}$, and the Fermi level of the composite (salt+surface) system is shown in dashed lines. The absolute position of the Fermi level in the composite system is very close to its position in the pure Ca surface (not shown); in other words, the adsorption of the salt did not affect the position of the Fermi level of $\mathrm{Ca}$. The orange and green lines correspond to the PDOS of the TFSI anions that are located on the right ( $1^{\text {st }}$ TFSI) and left $\left(2^{\text {nd }} \mathrm{TFSI}\right)$ sides of each inset geometry, respectively.

Since the LUMOs of the salt are primarily located above the Fermi level at $0 \mathrm{ps}$, electrons cannot transfer from the Ca surface to the anions. As such, the geometry of the salt is completely intact at $0 \mathrm{ps}$. As the simulation progresses, due to the changes in surface-salt interactions, the LUMO levels of the salt come closer to the Fermi level. At $1.3 \mathrm{ps}$, the LUMO of the salt (primarily composed of the second TFSI anion, depicted on the left side in each inset geometry) overlaps with the Fermi level, creating the possibility for a CT. At $1.38 \mathrm{ps}$, the second TFSI anion acquires electrons from the Ca surface and decomposes (the C-S bond is cleaved). From the PDOS plots at 1.3 and $1.38 \mathrm{ps}$, a clear crossing in the PDOS of the second TFSI anion (green line) across the Fermi level can be observed, indicating the transfer of an electron to this anion. The electron transfer process continues until $1.4 \mathrm{ps}$. At $1.5 \mathrm{ps}$, the PDOS of the first TFSI (orange-line) comes closer to the Fermi level, and by $1.7 \mathrm{ps}$, the electron transfer occurs, leading to the cleavage of the $\mathrm{C}-\mathrm{S}$ bond in the first TFSI (anion on the right side in each inset geometry). Overall, we find a one-to-one correspondence between the TD-PDOS and the salt decomposition process. 

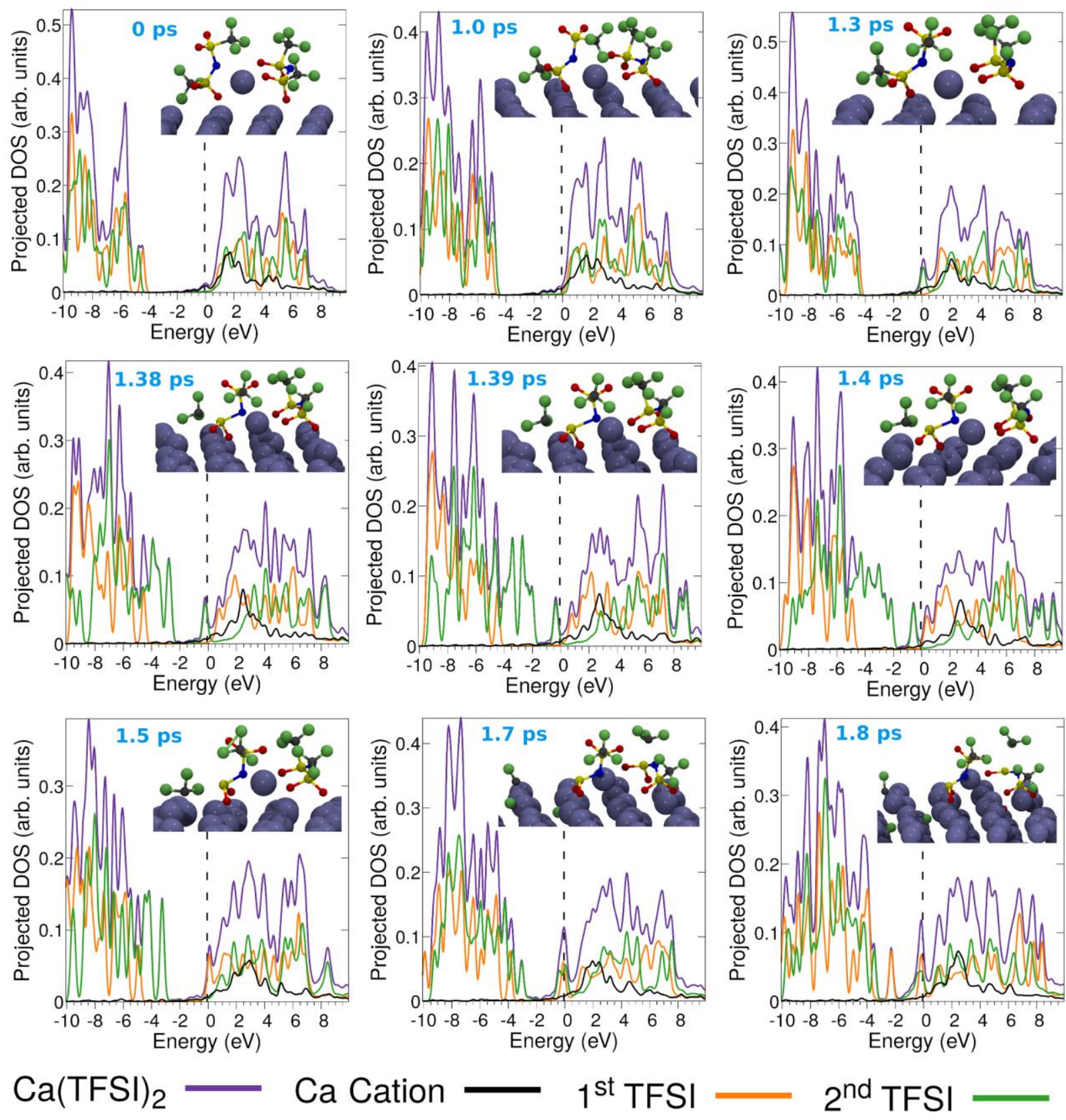

$2^{\text {nd }}$ TFSI

Figure 4: Time-dependent projected density of states (TD-PDOS) of the $\mathrm{Ca}[\mathrm{TFSI}]_{2}$ salt adsorbed on a $\mathrm{Ca}$ surface at $300 \mathrm{~K}$. Each panel shows the time step, PDOS, and the corresponding nuclear geometry. The Fermi level of the composite (salt+surface) system is shown in dashed lines. The orange and green lines correspond to the PDOS of the TFSI anions that are located on the right ( $\left.1^{\text {st }} \mathrm{TFSI}\right)$ and left ( $\left.2^{\text {nd }} \mathrm{TFSI}\right)$ sides of each geometry (in the insets), respectively. During the simulation, the anion on the left decomposed first (at around $1.38 \mathrm{ps}$ ), followed by the anion on the right (at around $1.7 \mathrm{ps}$ ).

Although Figure 4 only shows the cleavage of the $\mathrm{S}_{-} \mathrm{CF}_{3}$ bond, all other bonds (such as $\mathrm{N}-\mathrm{S}, \mathrm{S}-\mathrm{O}$, and C-F) were also cleaved during the NVT runs (both at 300 and $500 \mathrm{~K}$ ). Indeed, from 
our Cl-NEB calculations, we find that the transition state barriers for most of these bonds are in the range of 30-330 meV, often involving the elongation/cleavage of the N-S bond in the transition state (see Figures S3-S5). It is important to note that all these bond cleavage reactions are highly exothermic on a $\mathrm{Ca}$ surface, releasing up to 1-4 eV of energy (see Figures S3-S5). As a consequence, a bond-breaking event catalyzes the further dissociation of other bonds, as observed in our NVT simulations. A similar TD-PDOS analysis for the $\mathrm{Ca}\left[\mathrm{CB}_{11} \mathrm{H}_{12}\right]_{2}$ salt is presented in Figure S7, where we observed only minor changes in the PDOS with time, resulting in the absence of a CT between the Ca surface and the salt. Also, from our CI-NEB calculations, we find that the transition state barrier for $\mathrm{B}-\mathrm{B}$ bond cleavage in $\mathrm{Ca}\left[\mathrm{CB}_{11} \mathrm{H}_{12}\right]_{2}$ is $\sim 1.1 \mathrm{eV}$ (see Figure S6). Finally, it is important to mention that unlike the TD-PDOS calculations, the groundstate PDOS calculations did not provide any rationale for the observed stability differences among salts (see Figure S8). As such, our results strongly suggest that the inclusion of dynamics is essential for understanding the stability of salt-Ca interactions in these systems.

\section{Stability of Solvents on a Calcium Electrode Surface}

For reversible $\mathrm{Ca}$ deposition, apart from the availability of salts with good thermal and electrochemical stability, it is equally important to select solvents that would not decompose on the highly reductive $\mathrm{Ca}$ surface. To this end, we examined the stability of $\mathrm{EC}, \mathrm{PC}$, and G4 solvents on a Ca surface. Figure 5 presents geometries of the solvent-Ca interfaces at the initial and final steps of an NVT simulation conducted at $300 \mathrm{~K}$. Following previous works on solvent-surface interfaces, ${ }^{27,33,41}$ a vacuum space was not incorporated along the $c$-direction of the simulation cell, which allows the solvent molecules to interact with both sides of the six-layer Ca surface. Among the three solvents that we studied, G4 exhibited superior stability over the carbonate (EC and PC) solvents both at 300 and $500 \mathrm{~K}$ (see Figure S9). We note that $500 \mathrm{~K}$ is within the liquidus range of EC, PC, and G4 solvents. ${ }^{11}$ Also, $500 \mathrm{~K}\left(=226.85^{\circ} \mathrm{C}\right)$ is well below the boiling point of all of these solvents, which are 238,242 , and $275^{\circ} \mathrm{C}$ for $\mathrm{EC}, \mathrm{PC}$, and $\mathrm{G} 4$, respectively.

From our TD-CT analysis (Figure 6), we find that the remarkable stability of G4 stems from its higher reductive stability compared to EC and PC. Indeed, while both the EC and PC solvents acquired around 6-25 electrons from the Ca surface, there was no appreciable charge transfer (< 0.2 electrons) between G4 and the Ca surface even at $500 \mathrm{~K}$. From our Cl-NEB calculations, we find that the reaction barriers for the cleavage of various bonds in the EC and PC molecules on a Ca surface are comparable to energy fluctuations at room temperature (20-70 $\mathrm{meV}$, see figures S11-S18), explaining the facile decomposition of these molecules on a $\mathrm{Ca}$ surface. On the other hand, the cleavage barriers for the bonds in the G4 molecule are roughly an order of magnitude (165-265 meV) higher than energy fluctuations at room temperature, reflecting their higher reductive stability.

Since our simulations at 300 and $500 \mathrm{~K}$ do not show any decomposition of $\mathrm{G} 4$ on a $\mathrm{Ca}$ surface (during the time scales of our simulation), we predict the absence of a passivation layer at the Ca-G4 interface. Earlier AIMD simulations by Balbuena and coworkers on 1,2dimethoxyethane (G1) (which has a similar chemical structure to G4) on a Li surface also showed the absence of passivation at the Li-G1 interface, ${ }^{34}$ in agreement with our results. In the absence 
of passivation, there would be a facile and reversible calcium deposition on a Ca surface. However, it is also worth noting that the solvation of the $\mathrm{G} 4$ molecules to the $\mathrm{Ca}^{2+}$ cation can potentially impact the electrochemical deposition. Hahn et al. demonstrated that the coordination strength between the glyme solvent molecules and $\mathrm{Ca}^{2+}$ cation in $\mathrm{Ca}(\mathrm{TFSI})_{2}$ electrolytes is critical to the electrochemical deposition of $\mathrm{Ca}^{42}$ The importance of the solvation of $\mathrm{Ca}^{2+}$ was also highlighted by previous studies on the cathodic stability of $\mathrm{Mg}^{2+}$-glyme solvation during $\mathrm{Mg}$ deposition. Lautar et al. also suggested that the solvated $\left[\mathrm{Mg}(\mathrm{G} 1)_{3}\right]^{2+}$ cation could cathodically decompose on the Mg surface. ${ }^{43}$ Seguin et al. showed that solvated glyme molecules (G1, diglyme, and triglyme in their study) can be decomposed via cleavage of a non-terminal C-O bond by the partially-reduced $\mathrm{Mg}^{+}$during $\mathrm{Mg}$ deposition. ${ }^{44} \mathrm{Yu}$ et al. also suggested that $\mathrm{Mg}$ electrode surface impurities such as under-coordinated $\mathrm{Mg}$ can catalyze the decomposition of solvated diglyme molecules. ${ }^{45}$ Overall, our work confirms the chemical stability of G4 in Ca-ion electrolytes and calls for additional studies to probe the stability at the $\mathrm{Ca}$ /electrolyte interface under a cathodic potential.

(a)

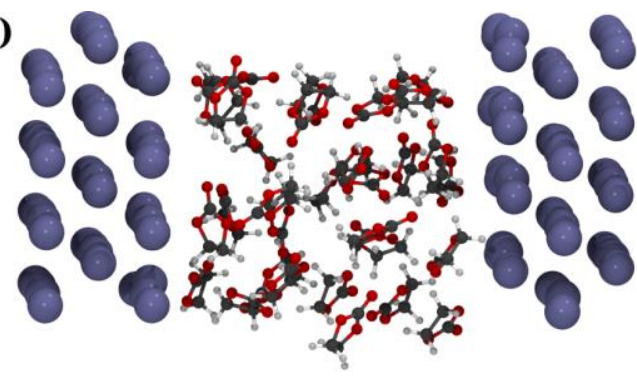

(b)

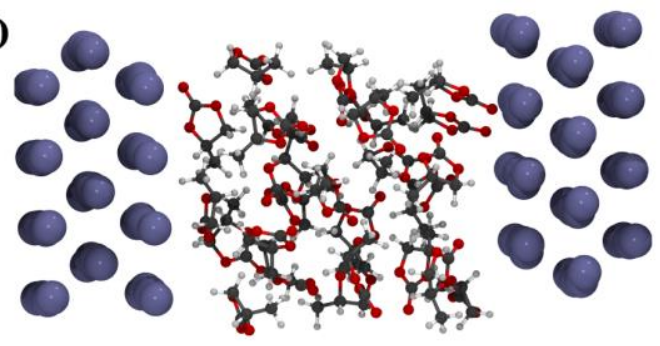

(c)

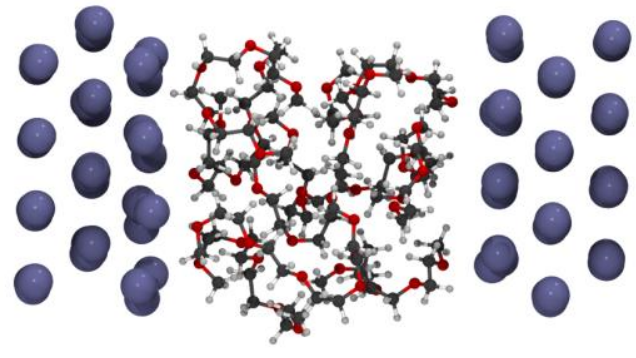

(d)

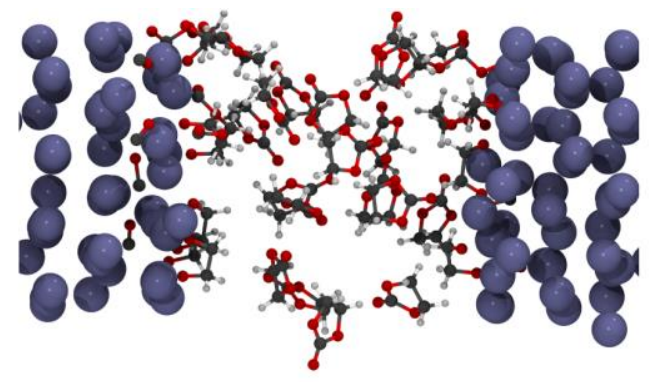

(e)

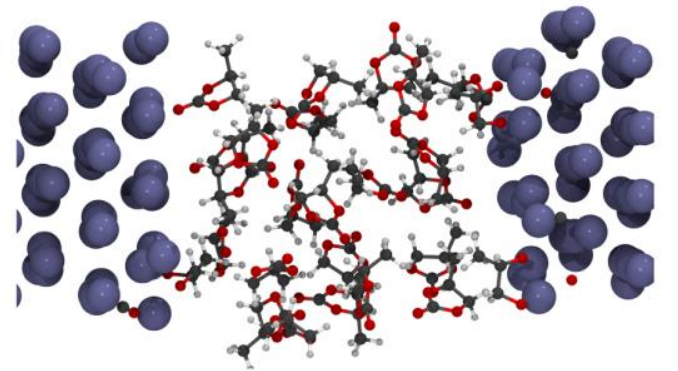

(f)

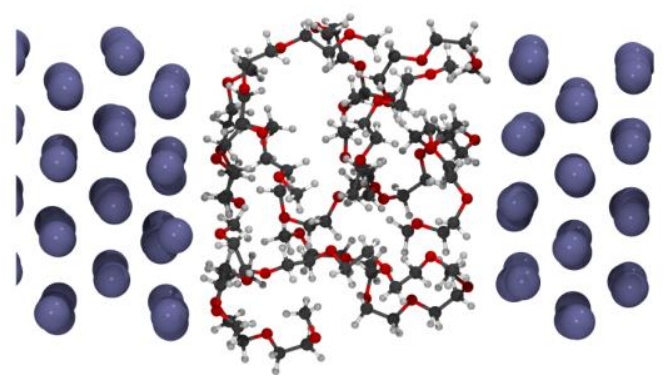

Figure 5: Geometries of different solvent-surface interfaces at the beginning $(a, b$, and $c)$ and end ( $d$, e, and f) of an NVT simulation performed at $300 \mathrm{~K}$. All simulations were carried out for at least 10 picoseconds. While EC (d) and PC (e) solvents decomposed at $300 \mathrm{~K}$ to form an interphase with the Ca-surface, the G4 solvent (f) remained intact throughout the simulation, indicating its superior stability over the carbonate solvents. 

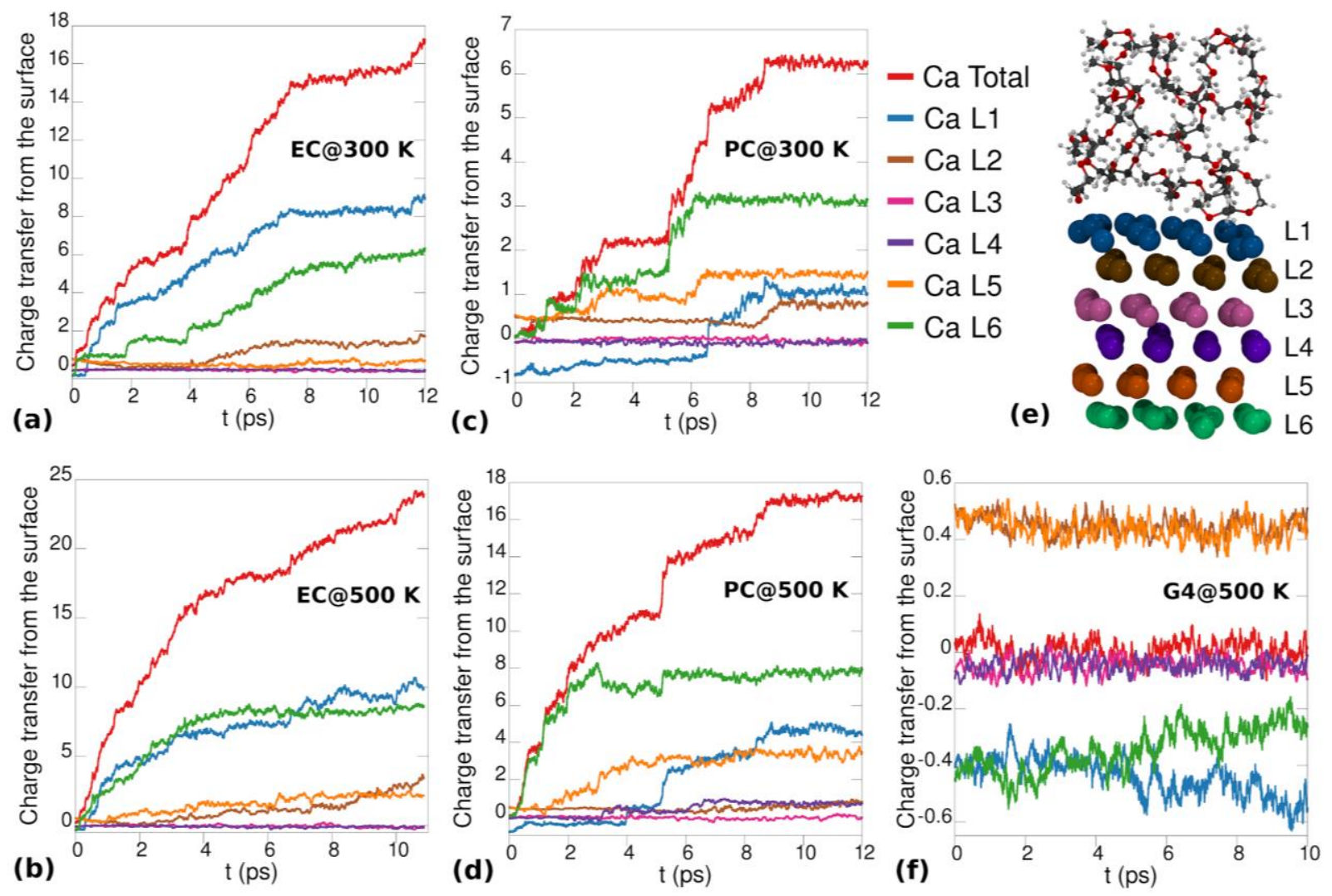

Figure 6: Time-dependent charge-transfer (TD-CT) from the calcium surface to $(a, b) E C$, (c, d) PC solvents at 300 and $500 \mathrm{~K}$, and (f) G4 solvent at $500 \mathrm{~K}$. Panel (e) shows the geometry of the G4 solvent on top of the Ca surface after $10 \mathrm{ps}$ of an NVT simulation at $500 \mathrm{~K}$. The six layers of the calcium surface (L1-L6) are depicted with the same colors as in panels a-d and f. Both the EC and PC solvents gained electrons from the Ca surface and decomposed at both 300 and 500 K. G4 did not accept any electrons (it has the highest reductive stability) from the $\mathrm{Ca}$ surface at either of the temperatures (see Figure S10 for the TD-CT plot of the G4-Ca interface at $300 \mathrm{~K}$ ). In all cases, most of the electrons were transferred from the Ca layers that are in direct contact with the solvent (Ca L1 and Ca L6).

Figure 7 shows the degradation mechanisms of EC and PC solvents observed in our BOMD simulations at 300 and $500 \mathrm{~K}$. For both $\mathrm{EC}$ and $\mathrm{PC}$ at $500 \mathrm{~K}$, we observed the generation of either $\mathrm{CO}$ or $\mathrm{CO}_{3}{ }^{2-}$ fragments, depending on whether the electrons transfer to $\mathrm{EC}$ in a sequential (Figures $7 \mathrm{a}$ to $7 \mathrm{~d}$ or Figures $7 \mathrm{f}$ to $7 \mathrm{i}$ ) or concerted manner (Figures $7 \mathrm{a} / 7 \mathrm{e}$, and $7 \mathrm{f} / 7 \mathrm{j}$ ), respectively. At $300 \mathrm{~K}$, however, we only observed the generation of $\mathrm{CO}$ but not the generation of $\mathrm{CO}_{3}{ }^{2-}$ fragment during our simulation time-scales. Similar decomposition mechanisms for the EC solvent were earlier observed on the $\mathrm{Li}$ and $\mathrm{Ca}$ surfaces. ${ }^{27,33}$ For example, Balbuena and coworkers showed that the dissociation of $\mathrm{CO}$ and $\mathrm{CO}_{3}{ }^{2-}$ fragments from $\mathrm{EC}$ molecules was triggered by an electron transfer from the Li surface. For EC at $500 \mathrm{~K}$, we also observed the decomposition of the $\mathrm{CO}$ molecule into carbon and oxygen atoms, and the formation of a $\mathrm{CO}$ 
dimer (Figure 7 inset). For $\mathrm{PC}$, we observed the formation of $\mathrm{CO}_{2}$ and oxygen atoms at $500 \mathrm{~K}$ (Figures $7 \mathrm{k}$ and $7 \mathrm{l}$ ). Since an elevated temperature is often used as a simulation parameter to explore the phase space within a short simulation duration, we expect that the products obtained in our $500 \mathrm{~K}$ simulations would also be observed in the experiments at room temperature.

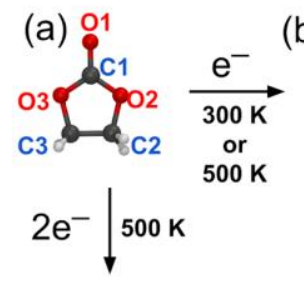

(b)

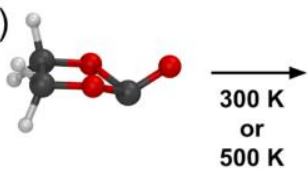

(e)

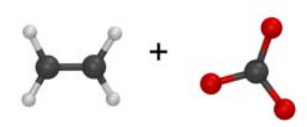

(c)

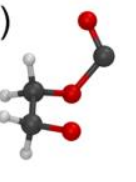

(d)

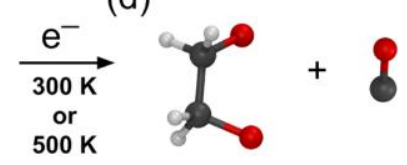

EC

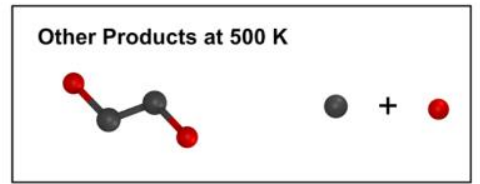

(f)

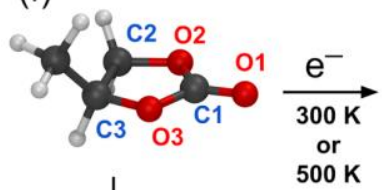

$2 e^{-} \downarrow 500 k$

(j)

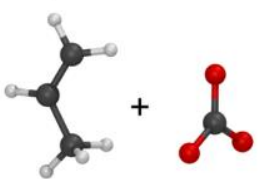

(g)

(h)

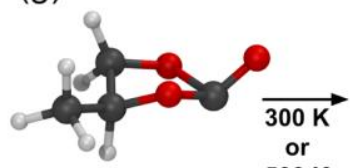

(k)

(i)

PC

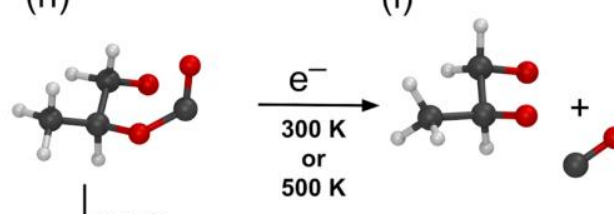

$500 \mathrm{~K}$

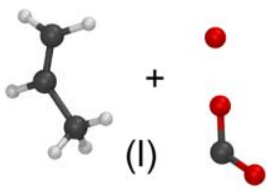

Figure 7: Various steps depicting the decomposition mechanisms of EC ( $a$ to $e$ ) and $\mathrm{PC}(f$ to $)$, solvents as observed in our BOMD simulations. For both $\mathrm{EC}$ and $\mathrm{PC}$ at $500 \mathrm{~K}$, we observed the formation of either $\mathrm{CO}$ or $\mathrm{CO}_{3}{ }^{2-}$ fragments, depending on whether the electrons transfer to $\mathrm{EC}$ in a sequential or concerted manner, respectively. For $\mathrm{EC}$ at $500 \mathrm{~K}$, apart from the products at $300 \mathrm{~K}$, we also observed either the decomposition of the $\mathrm{CO}$ molecule into carbon and oxygen atoms or the formation of a CO dimer. For PC at $500 \mathrm{~K}$, apart from the products at $300 \mathrm{~K}$, we observed the formation of $\mathrm{CO}_{2}$ and oxygen atoms.

It is interesting to note that there is a one-to-one correspondence between the number of electrons transferred from the Ca surface and the number of bonds broken in the solvent layer. For example, at $300 \mathrm{~K}$, the PC solvent layer gained roughly six electrons in 12 picoseconds. Accordingly, we find that the carbonyl groups of three PC molecules dissociated (each carbonyl carbon forms two bonds with oxygen atoms in the PC molecule. As such, a total of six bonds were dissociated, which is equal to the number of electrons transferred). Also, we find that the individual electron-transfer events can be distinctly observed from the TD-CT plots. As shown in Figure 6c, the first electron transferred at $\sim 1.1 \mathrm{ps}$. This transfer resulted in the bending of the carbonyl group 
(Figure $7 \mathrm{~g}$ ) followed by the dissociation of one of the $\mathrm{C} 1-\mathrm{O} 2 / \mathrm{C} 1-\mathrm{O} 3$ bonds of the $\mathrm{PC}$ molecule (Figure $7 \mathrm{~h}$ ). Next, at $\sim 2 \mathrm{ps,} \mathrm{another} \mathrm{electron} \mathrm{transfer} \mathrm{occurs,} \mathrm{resulting} \mathrm{in} \mathrm{the} \mathrm{complete} \mathrm{dissociation}$ of the $\mathrm{CO}$ group from the PC (Figure 7i). Similarly, electron transfer events at 5 and 6 ps and at 6.5 and 8.5 ps resulted in the dissociation of the $\mathrm{CO}$ groups in two other PC molecules. Together, these analyses provide a clear mechanistic understanding of the decomposition behavior of various salts and solvents on a Ca surface.

\section{Conclusions}

In summary, we have carried out BOMD simulations to examine the stability of various technologically relevant salts and solvents for CIBs. Our simulations suggest that the G4 solvent and $\mathrm{Ca}\left[\mathrm{CB}_{11} \mathrm{H}_{12}\right]_{2}$ salt have the highest reductive stability at the $\mathrm{Ca}$ surface over a wide range of temperatures (they exhibit superior reductive stability at both 300 and $500 \mathrm{~K}$ ). Among the other salts, the $\mathrm{Ca}\left[\mathrm{B}(\mathrm{hfip})_{4}\right]_{2}$ salt showed reasonable stability during the $10 \mathrm{ps}$ simulation propagation time. We strongly anticipate that $\mathrm{Ca}$ can be reversibly deposited in glyme solvents using either the $\mathrm{Ca}\left[\mathrm{B}(\mathrm{hfip})_{4}\right]_{2}$ or $\mathrm{Ca}\left[\mathrm{CB}_{11} \mathrm{H}_{12}\right]_{2}$ salt.

Both salts $\left(\mathrm{Ca}[\mathrm{TFSI}]_{2}\right.$ and $\left.\mathrm{Ca}\left[\mathrm{PF}_{6}\right]_{2}\right)$ and solvents (EC and $\left.\mathrm{PC}\right)$ exhibited poor reductive stability and decomposed at both 300 and $500 \mathrm{~K}$. As such, we find them to be less suitable for CIBs. Detailed mechanisms of their decomposition were made possible using time-dependent structural analysis techniques, including TD-PDOS, TD-CT, and CI-NEB analyses. Most importantly, we find that static electronic structure calculations alone cannot provide a rationale for the superior stability of $\mathrm{Ca}\left[\mathrm{CB}_{11} \mathrm{H}_{12}\right]_{2}$ over the $\mathrm{Ca}[\mathrm{TFSI}]_{2}$ and $\left.\mathrm{Ca}[\mathrm{PF}]_{2}\right]_{2}$ salts, and the inclusion of dynamical effects is essential. Since the BOMD simulations used in this work inherently capture these dynamical effects, we recommend the use of these techniques (as opposed to only static DFT calculations) for predicting salt/solvent stability and obtaining a more holistic understanding of these systems. Taken together, our work provides a rational path for designing next-generation multivalent electrolytes for energy storage applications (particularly calcium batteries), which require exceptional electrolyte reductive stability to achieve their maximum potential.

\section{Supporting Information}

Additional computational details, stability and TD-CT plots of salts at $500 \mathrm{~K}$, minimum energy paths for the dissociation of various bonds of salt and solvent molecules on a Ca-surface, TDPDOS plots of the $\mathrm{Ca}\left[\mathrm{CB}_{11} \mathrm{H}_{12}\right]_{2}$ salt, ground-state PDOS plots of isolated salts and salts adsorbed on the Ca-surface, variation in the solvent/salt distance from the Ca-surface, and supporting figures and NVT input file. 


\section{Acknowledgements}

S. S. R. K. C. Y., H. K., and B. M. W. acknowledge support by the U.S. Department of Energy, Office of Science, Early Career Research Program under Award No. DE-SC0016269. J. G. acknowledges support by the National Science Foundation under grant No. DMR-2004497.

\section{References}

(1) Manthiram, A. A Reflection on Lithium-Ion Battery Cathode Chemistry. Nat. Commun. 2020, $11(1), 1550$.

(2) Arroyo-de Dompablo, M. E.; Ponrouch, A.; Johansson, P.; Palacín, M. R. Achievements, Challenges, and Prospects of Calcium Batteries. Chem. Rev. 2020, 120 (14), 6331-6357.

(3) Canepa, P.; Sai Gautam, G.; Hannah, D. C.; Malik, R.; Liu, M.; Gallagher, K. G.; Persson, K. A.; Ceder, G. Odyssey of Multivalent Cathode Materials: Open Questions and Future Challenges. Chem. Rev. 2017, $117(5)$, 4287-4341.

(4) Baba, T.; Sodeyama, K.; Kawamura, Y.; Tateyama, Y. Li-lon Transport at the Interface between a Graphite Anode and LiCO Solid Electrolyte Interphase: Ab Initio Molecular Dynamics Study. Phys. Chem. Chem. Phys. 2020, 22 (19), 10764-10774.

(5) Olivetti, E. A.; Ceder, G.; Gaustad, G. G.; Fu, X. Lithium-Ion Battery Supply Chain Considerations: Analysis of Potential Bottlenecks in Critical Metals. Joule 2017, 1 (2), 229243.

(6) Grey, C. P.; Tarascon, J. M. Sustainability and in Situ Monitoring in Battery Development. Nature Materials 2017, 16 (1), 45-56.

(7) Vaalma, C.; Buchholz, D.; Weil, M.; Passerini, S. A Cost and Resource Analysis of SodiumIon Batteries. Nature Reviews Materials 2018, 3 (4).

(8) Li, M.; Lu, J. Cobalt in Lithium-Ion Batteries. Science 2020, 367 (6481), 979-980.

(9) Okoshi, M.; Chou, C.-P.; Nakai, H. Theoretical Analysis of Carrier Ion Diffusion in Superconcentrated Electrolyte Solutions for Sodium-Ion Batteries. J. Phys. Chem. B 2018, $122(9), 2600-2609$.

(10) Wang, D.; Gao, X.; Chen, Y.; Jin, L.; Kuss, C.; Bruce, P. G. Plating and Stripping Calcium in an Organic Electrolyte. Nature Materials 2018, 17 (1), 16-20.

(11) Ponrouch, A.; Frontera, C.; Bardé, F.; Palacín, M. R. Towards a Calcium-Based Rechargeable Battery. Nat. Mater. 2016, 15 (2), 169-172.

(12) Li, Z.; Fuhr, O.; Fichtner, M.; Zhao-Karger, Z. Towards Stable and Efficient Electrolytes for Room-Temperature Rechargeable Calcium Batteries. Energy \& Environmental Science 2019, 12 (12), 3496-3501.

(13) Shyamsunder, A.; Blanc, L. E.; Assoud, A.; Nazar, L. F. Reversible Calcium Plating and Stripping at Room Temperature Using a Borate Salt. ACS Energy Letters 2019, 4 (9), 2271-2276.

(14) Lipson, A. L.; Pan, B.; Lapidus, S. H.; Liao, C.; Vaughey, J. T.; Ingram, B. J. Rechargeable Ca-Ion Batteries: A New Energy Storage System. Chemistry of Materials 2015, 27 (24), 8442-8447.

(15) Aurbach, D.; Skaletsky, R.; Gofer, Y. The Electrochemical Behavior of Calcium Electrodes in a Few Organic Electrolytes. Journal of The Electrochemical Society 1991, 138 (12), 3536-3545.

(16) Gao, X.; Liu, X.; Mariani, A.; Elia, G. A.; Lechner, M.; Streb, C.; Passerini, S. AlkoxyFunctionalized Ionic Liquid Electrolytes: Understanding Ionic Coordination of Calcium Ion Speciation for the Rational Design of Calcium Electrolytes. Energy \& Environmental 
Science 2020, 13 (8), 2559-2569.

(17) Jay, R.; Tomich, A. W.; Zhang, J.; Zhao, Y.; De Gorostiza, A.; Lavallo, V.; Guo, J. Comparative Study of $\mathrm{Mg}(\mathrm{CB} 11 \mathrm{H} 12) 2$ and $\mathrm{Mg}(\mathrm{TFSI}) 2$ at the Magnesium/Electrolyte Interface. ACS Applied Materials \& Interfaces 2019, 11 (12), 11414-11420.

(18) Zhao-Karger, Z.; Liu, R.; Dai, W.; Li, Z.; Diemant, T.; Vinayan, B. P.; Minella, C. B.; Yu, X.; Manthiram, A.; Jürgen Behm, R.; Ruben, M.; Fichtner, M. Toward Highly Reversible Magnesium-Sulfur Batteries with Efficient and Practical Mg[B(hfip)4]2Electrolyte. ACS Energy Letters 2018, 3 (8), 2005-2013.

(19) Perdew, J. P.; Burke, K.; Ernzerhof, M. Generalized Gradient Approximation Made Simple. Physical Review Letters. 1996, pp 3865-3868.

(20) VandeVondele, J.; Hutter, J. Gaussian Basis Sets for Accurate Calculations on Molecular Systems in Gas and Condensed Phases. J. Chem. Phys. 2007, $127(11)$, 114105.

(21) VandeVondele, J.; Krack, M.; Mohamed, F.; Parrinello, M.; Chassaing, T.; Hutter, J. Quickstep: Fast and Accurate Density Functional Calculations Using a Mixed Gaussian and Plane Waves Approach. Computer Physics Communications. 2005, pp 103-128.

(22) Goedecker, S.; Teter, M.; Hutter, J. Separable Dual-Space Gaussian Pseudopotentials. Phys. Rev. B Condens. Matter 1996, 54 (3), 1703-1710.

(23) Krack, M. Pseudopotentials for $\mathrm{H}$ to Kr Optimized for Gradient-Corrected ExchangeCorrelation Functionals. Theoretical Chemistry Accounts. 2005, pp 145-152.

(24) Grimme, S.; Ehrlich, S.; Goerigk, L. Effect of the Damping Function in Dispersion Corrected Density Functional Theory. J. Comput. Chem. 2011, 32 (7), 1456-1465.

(25) Ha, S.-Y.; Lee, Y.-W.; Woo, S. W.; Koo, B.; Kim, J.-S.; Cho, J.; Lee, K. T.; Choi, N.-S. Magnesium(II) Bis(trifluoromethane Sulfonyl) Imide-Based Electrolytes with Wide Electrochemical Windows for Rechargeable Magnesium Batteries. ACS Appl. Mater. Interfaces 2014, 6 (6), 4063-4073.

(26) Ma, Z.; Kar, M.; Xiao, C.; Forsyth, M.; MacFarlane, D. R. Electrochemical Cycling of Mg in Mg[TFSI] 2 /tetraglyme Electrolytes. Electrochemistry Communications. 2017, pp 29-32.

(27) Young, J.; Kulick, P. M.; Juran, T. R.; Smeu, M. Comparative Study of Ethylene Carbonate-Based Electrolyte Decomposition at $\mathrm{Li}, \mathrm{Ca}$, and Al Anode Interfaces. ACS Applied Energy Materials. 2019, pp 1676-1684.

(28) Aurbach, D.; Markovsky, B.; Shechter, A.; Ein-Eli, Y.; Cohen, H. A Comparative Study of Synthetic Graphite and Li Electrodes in Electrolyte Solutions Based on Ethylene Carbonate-Dimethyl Carbonate Mixtures. Journal of The Electrochemical Society. 1996, pp 3809-3820.

(29) Dahbi, M.; Ghamouss, F.; Tran-Van, F.; Lemordant, D.; Anouti, M. Comparative Study of EC/DMC LiTFSI and LiPF6 Electrolytes for Electrochemical Storage. Journal of Power Sources. 2011, pp 9743-9750.

(30) Pappenfus, T. M.; Henderson, W. A.; Owens, B. B.; Mann, K. R.; Smyrl, W. H. Complexes of Lithium Imide Salts with Tetraglyme and Their Polyelectrolyte Composite Materials. Journal of The Electrochemical Society. 2004, p A209-A215.

(31) Doi, T.; Masuhara, R.; Hashinokuchi, M.; Shimizu, Y.; Inaba, M. Concentrated LiPF6/PC Electrolyte Solutions for 5-V LiNi0.5Mn1.5O4 Positive Electrode in Lithium-Ion Batteries. Electrochimica Acta. 2016, pp 219-224.

(32) Wang, M.; Jiang, C.; Zhang, S.; Song, X.; Tang, Y.; Cheng, H.-M. Reversible Calcium Alloying Enables a Practical Room-Temperature Rechargeable Calcium-Ion Battery with a High Discharge Voltage. Nat. Chem. 2018, 10 (6), 667-672.

(33) Camacho-Forero, L. E.; Smith, T. W.; Bertolini, S.; Balbuena, P. B. Reactivity at the Lithium-Metal Anode Surface of Lithium-Sulfur Batteries. J. Phys. Chem. C 2015, 119 (48), 26828-26839.

(34) Camacho-Forero, L. E.; Balbuena, P. B. Effects of Charged Interfaces on Electrolyte 
Decomposition at the Lithium Metal Anode. Journal of Power Sources. 2020, p 228449.

(35) Keyzer, E. N.; Matthews, P. D.; Liu, Z.; Bond, A. D.; Grey, C. P.; Wright, D. S. Synthesis of $\mathrm{Ca}(\mathrm{PF} 6) 2$, Formed via Nitrosonium Oxidation of Calcium. Chemical Communications. 2017, pp 4573-4576.

(36) Keyzer, E. N.; Matthews, P. D.; Liu, Z.; Bond, A. D.; Grey, C. P.; Wright, D. S. Correction: Synthesis of $\mathrm{Ca}(\mathrm{PF} 6) 2$, Formed via Nitrosonium Oxidation of Calcium. Chemical Communications. 2018, pp 12271-12271.

(37) Ando, Y.; Kawamura, Y.; Ikeshoji, T.; Otani, M. Electrochemical Reduction of an Anion for Ionic-Liquid Molecules on a Lithium Electrode Studied by First-Principles Calculations. Chemical Physics Letters. 2014, pp 240-244.

(38) Baskin, A.; Prendergast, D. Exploration of the Detailed Conditions for Reductive Stability of Mg(TFSI)2 in Diglyme: Implications for Multivalent Electrolytes. The Journal of Physical Chemistry C. 2016, pp 3583-3594.

(39) Zheng, Y.; Soto, F. A.; Ponce, V.; Seminario, J. M.; Cao, X.; Zhang, J.-G.; Balbuena, P. B. Localized High Concentration Electrolyte Behavior near a Lithium-metal Anode Surface. Journal of Materials Chemistry A. 2019, pp 25047-25055.

(40) Kumar, N.; Siegel, D. J. Interface-Induced Renormalization of Electrolyte Energy Levels in Magnesium Batteries. J. Phys. Chem. Lett. 2016, 7 (5), 874-881.

(41) Li, Y.; Leung, K.; Qi, Y. Computational Exploration of the Li-Electrode| Electrolyte Interface in the Presence of a Nanometer Thick Solid-Electrolyte Interphase Layer. Acc. Chem. Res. 2016, 49 (10), 2363-2370.

(42) Hahn, N. T.; Driscoll, D. M.; Yu, Z.; Sterbinsky, G. E.; Cheng, L.; Balasubramanian, M.; Zavadil, K. R. Influence of Ether Solvent and Anion Coordination on Electrochemical Behavior in Calcium Battery Electrolytes. ACS Appl. Energy Mater. 2020, 3 (9), 8437-8447.

(43) Kopač Lautar, A.; Bitenc, J.; Rejec, T.; Dominko, R.; Filhol, J.-S.; Doublet, M.-L. Electrolyte Reactivity in the Double Layer in Mg Batteries: An Interface Potential-Dependent DFT Study. J. Am. Chem. Soc. 2020, 142 (11), 5146-5153.

(44) Seguin, T. J.; Hahn, N. T.; Zavadil, K. R.; Persson, K. A. Elucidating Non-Aqueous Solvent Stability and Associated Decomposition Mechanisms for Mg Energy Storage Applications From First-Principles. Front Chem 2019, 7, 175.

(45) Yu, Y.; Baskin, A.; Valero-Vidal, C.; Hahn, N. T.; Liu, Q.; Zavadil, K. R.; Eichhorn, B. W.; Prendergast, D.; Crumlin, E. J. Instability at the Electrode/Electrolyte Interface Induced by Hard Cation Chelation and Nucleophilic Attack. Chem. Mater. 2017, 29 (19), 8504-8512.

\section{Table of Contents (TOC) graphic}
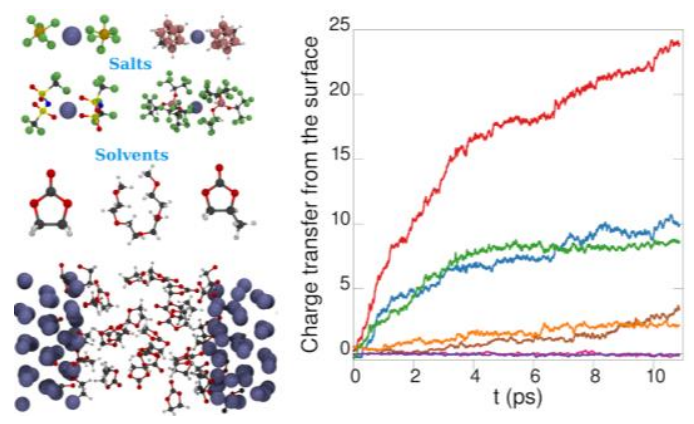